\title{
AVALIAÇÃO DA ALIMENTAÇÃO ESCOLAR OFERECIDA AOS ALUNOS DO ENSINO FUNDAMENTAL DAS ESCOLAS MUNICIPAIS DE LAVRAS, MG ${ }^{1}$
}

\author{
Evaluation of school meals offered to elementary students of municipal schools of Lavras, MG \\ Eliete Fernandes Flávio², Maria de Fátima Píccolo Barcelos ${ }^{3}$, \\ Marcelo Ângelo Cirillo ${ }^{4}$, Alessandra Honório Ribeiro ${ }^{5}$
}

\begin{abstract}
RESUMO
Objetivou-se no presente estudo avaliar a alimentação escolar (AE) oferecida aos alunos do ensino fundamental (EF) nas unidades escolares municipais (UEM), urbanas (EU) e rurais (ER), de Lavras, MG, de forma gratuita, em função do repasse financeiro do Programa Nacional de Alimentação Escolar (PNAE), quanto à composição química e atendimento da meta de fornecer $15 \%$ das necessidades nutricionais dos alunos. A coleta de amostras para a análise da composição química foi realizada aleatoriamente, em todas as UEM durante o ano de 2004. A análise da AE apresentou valores diários médios de 189kcal, 7,5g de proteína, 72,9mg de Ca, 16,7mg de $\mathrm{Mg}, 2,2 \mathrm{mg}$ de $\mathrm{Fe}$ e 1,4mg de $\mathrm{Zn}$. Para o atendimento da meta de fornecer 15\% das necessidades nutricionais, do total de dezesseis escolas estudadas, o teor de energia e cálcio encontrava-se abaixo do recomendado em quinze escolas, sendo que apenas uma do meio urbano atendeu a proporção de energia e uma do meio rural atendeu quanto ao teor de cálcio; para o magnésio só três escolas, duas urbanas e uma rural, atingiram a meta; o oferecimento de proteína e ferro foi atingido por todas as escolas estudadas. Concluí-se que a meta de fornecer $15 \%$ das NN na alimentação escolar não foi totalmente atingida, pois a maioria das adequações ficou fora da faixa recomendada pelo PNAE.
\end{abstract}

Termos para indexação: Composição química; necessidades nutricionais; PNAE; criança; adolescente.

\section{ABSTRACT}

The present work had the aim of evaluating school feeding (AE) offered to students of elementary school in the city school (EF) (UEM), both urban (EU) and rural (ER) units of Lavras, MG, in a free form, as related to the financial repassing of the Programa Nacional de Alimentação Escolar (PNAE) (National Feeding School Program) as to the chemical composition and attainment of the goal of meeting $15 \%$ of the nutrient allowances of these students. The collection of samples for the analysis of chemical composition was accomplished randomly, in all the UEM during the year of 2004. The analysis of the AE presented daily average values of $189 \mathrm{kcal}, 7.5 \mathrm{~g}$ of protein, $72.9 \mathrm{mg}$ of $\mathrm{Ca}, 16.7 \mathrm{mg}$ of $\mathrm{Mg}, 2.2 \mathrm{mg}$ of $\mathrm{Fe}$ and $1.4 \mathrm{mg}$ of $\mathrm{Zn}$. For the attendance of the goal to supply to $15 \%$ of the nutritional necessities, of the total of sixteen studied schools, the content of energy and calcium met below of the recommended in fifteen schools, being one of the urban school met the ratio of energy and one of the rural school was met as to the calcium content; for magnesium only three schools, two urban school and a rural school, had reached the goal; the goal of supply protein and iron was reached by the schools studied me concluded that the goal to supply $15 \%$ of the NN in the school meals was not reached, therefore the majority of the adequacies was outside of the band recommended for the PNAE.

Index terms: Chemical evaluation; nutrient allowances; PNAE; children; adolescent.

(Recebido em 6 de Junho de 2006 e aprovado em 19 de junho de 2007)

\section{INTRODUÇÃO}

A alimentação adequada da criança e do adolescente garante qualidade na vida adulta. As crianças e adolescentes, além da alimentação domiciliar, têm o direito de receber a alimentação escolar oferecida gratuitamente nas escolas públicas em função do repasse financeiro do
Programa Nacional de Alimentação Escolar (PNAE). O PNAE prevê a transferência de recursos financeiros às escolas públicas, destinados à aquisição de gêneros alimentícios para o oferecimento da alimentação escolar aos alunos matriculados na educação infantil (em creches e em pré-escolas) e no ensino fundamental das escolas da rede pública que constem no censo escolar realizado pelo

\footnotetext{
${ }^{1}$ Extraído da tese de doutorado apresentada pela primeira autora à Universidade Federal de Lavras/UFLA, Caixa Postal 3037 - $37200-000$ - Lavras, MG ${ }^{2}$ Nutricionista, Doutora em Ciência dos Alimentos - Hospital Universitário Clemente de Faria/HUCF - Universidade Estadual de Montes Claros/ UNIMONTES - Campus Universitário Professor Darcy Ribeiro - Vila Mauricéia - Cx. P. 126 - 39401-089 - Montes Claros, MG - elieteflavio@gmail.com ${ }^{3}$ Doutora em Alimentos e Nutrição, Professora Adjunto - Departamento de Ciência dos Alimentos/DCA - Universidade Federal de Lavras/UFLA - Cx. P. 3037 - 37200-000 - Lavras, MG - piccolob@ufla.br

${ }^{4}$ Doutor em Estatística e Experimentação Agropecuária, Professor Adjunto - Departamento de Ciência Exatas/DEX - Universidade Federal de Lavras/ UFLA - Cx. P. 3037 - 37200-000 - Lavras, MG - marcelocirillo@hotmail.com

${ }_{5}^{5}$ utricionista - Departamento de Ciência dos Alimentos/DCA - Universidade Federal de Lavras/UFLA - Cx. P. 3037 - $37200-000$ - Lavras, MG
} 
Ministério da Educação (MEC), no ano anterior ao atendimento (BRASIL, 2004; FNDE, 2005).

O PNAE tem como proposta a suplementação das necessidades nutricionais diárias dos alunos matriculados, suprindo no mínimo, $15 \%$ delas, com vistas a garantir a implantação da Política de Segurança Alimentar e Nutricional e contribuir para a formação de bons hábitos alimentares, por meio da distribuição de refeições durante o intervalo das atividades escolares. Esse Programa vigora no Brasil há mais de 50 anos e destaca-se, entre os demais programas públicos de assistência alimentar, em dimensão e cobertura, pois atendeu, durante os 200 dias letivos do ano de 2004, a 37 milhões de crianças e adolescentes por dia, correspondendo a $22 \%$ da população brasileira (FNDE, 2005).

Em relação à utilização dos recursos financeiros destinados ao PNAE, a entidade executora deve destinar, no mínimo, $70 \%$ aos produtos básicos, priorizando os alimentos locais. $\mathrm{O}$ valor per capita da alimentação escolar atribuído aos alunos na pré-escola e ensino fundamental, no ano de 2004, foi de R \$ 0,15 (quinze centavos). Deve-se salientar que não existem diferenças quanto aos valores pagos para os alunos matriculados nas escolas urbanas e rurais do país (BRASIL, 2004; FNDE, 2005).

A alimentação escolar, para considerável parcela de alunos das escolas públicas, representa às vezes a única refeição diária (FNDE, 2005). Conhecer a composição química para avaliar se a meta de necessidades nutricionais (15\%) está sendo atendida é de grande importância, pois em estudos realizados foram verificadas inadequações quanto ao teor de nutrientes na merenda escolar (FLÁVIO, 2002; SALAY \& CARVALHO, 1995; SILVA, M., 1998). Levantamento sobre a AE oferecida a 625 alunos do EF, com idade entre 6 e 18 anos, matriculados em uma escola estadual de Lavras, MG, no ano de 2001, indicou que o valor energético era de $185,7 \mathrm{kcal} /$ dia e de proteínas de $6,5 \mathrm{~g} / \mathrm{dia}$, na porção diária da alimentação escolar,

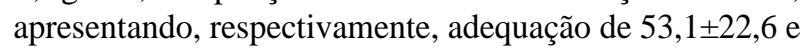
de $72,2 \% \pm 2,8$ em relação às metas de recomendações do PNAE (FLÁVIO, 2002).

Na região sudeste, mais precisamente na região sul do estado de Minas Gerais, está localizado o município de Lavras, MG, que no ano de 2004, contava mais de 15.000 alunos matriculados na rede pública de ensino. Desse total de alunos, 6.674 estavam matriculados no ensino fundamental das unidades escolares municipais.

A base econômica de Lavras, MG, estabelece-se no campo industrial e da agricultura, e destacam-se as culturas de café, milho, feijão, mandioca e frutas cítricas, principalmente a laranja e, ainda a pecuária leiteira (ALMG, 2005). O setor educacional destaca-se com escolas centenárias de ensino infantil, fundamental, médio e superior. O total de escolas municipais de ensino fundamental, no ano de 2004, apresentou-se da ordem de 16 unidades escolares, sendo onze urbanas e cinco núcleos (rurais) que foram alvo deste estudo. Objetivou-se, aqui, avaliar a composição química da alimentação escolar oferecida aos alunos do ensino fundamental, em todas as unidades escolares municipais (urbanas e rurais) de Lavras, MG e verificar se a meta de fornecer $15 \%$ das necessidades nutricionais dos alunos estava sendo atingida.

\section{MATERIAL E MÉTODOS}

Esse trabalho foi realizado pelo Departamento de Ciência dos Alimentos (DCA), da Universidade Federal de Lavras (UFLA) e tratou-se de um estudo sobre a avaliação da alimentação escolar oferecida aos alunos abrangendo as unidades escolares municipais (urbanas e rurais) de ensino fundamental (EF) de Lavras, MG, durante o ano de 2004, contando com a participação de 835 alunos.

\section{Local e delineamento da pesquisa}

A pesquisa foi realizada no município de Lavras, $\mathrm{MG}$, em todas as dezesseis unidades escolares municipais (UEM), urbanas e rurais de ensino fundamental (EF). O desenho amostral do presente estudo foi do tipo observacional e transversal, desenvolvido por meio de pesquisa por amostragem, nas unidades escolares municipais de Lavras, MG. Na composição da amostra foram incluídas todas as UEM, urbanas e rurais (onze escolas urbanas e cinco núcleos rurais) de EF de Lavras, MG. Núcleo é a denominação dada para as unidades localizadas na zona rural e que tenham uma determinada proximidade.

\section{Cálculo das necessidades nutricionais diárias dos alunos das unidades de ensino municipais de Lavras, MG}

A média das necessidades nutricionais $(\mathrm{NN})$ dos alunos do EF, para cada UEM foi calculada mediante os dados de idade e sexo de cada aluno participante do estudo. As recomendações nutricionais para proteína e minerais foram baseadas nas Dietary Reference Intakes-DRIs/2001 e DRIs/2002 (FISBERG et al., 2005) e as calorias na Recommended Dietary Allowances-RDA/1989 (NRC, 1989).

\section{Avaliação da alimentação escolar das UEM de Lavras, MG}

Em cada UEM foram coletadas, de forma aleatória/ mês, quatro amostras (alimentação escolar/dia), totalizando 64 amostras da merenda escolar. Após a coleta, as porções da AE foram conduzidas para o Laboratório de Bioquímica Nutricional/DCA, para serem pesadas e analisadas quimicamente. Todas as porções da $\mathrm{AE}$ distribuídas foram 
pesadas para o cálculo da porção média diária da preparação dietética oferecida, no dia pré-estipulado da coleta.

\section{a) Análise da composição química da alimentação escolar}

Foram determinados: umidade, cinza (minerais), lipídio, proteína, fibra total e extrato não nitrogenado (ENN calculada por diferença) das 64 amostras de alimentação escolar coletadas. Os métodos utilizados foram os propostos pela AOAC (1990), com exceção da fração fibra, que foi determinada segundo o método gravimétrico, após digestão em meio ácido, conforme Kamer \& Ginkel (1952). A proteína foi determinada pelo método semimicro Kjeldahl, multiplicando-se o nitrogênio pelo fator 6,25. $\mathrm{O}$ valor energético da $\mathrm{AE}$ foi calculado a partir dos fatores de conversão de Atwater correspondentes para proteínas, lipídios e carboidratos, 4, 9 e 4kcal/g (OSBORNE \& VOOGT, 1978).

\section{b) Análise da composição mineral}

Realizaram-se análises dos seguintes minerais: $\mathrm{Ca}$, $\mathrm{Mg}$, Fe e Zn, conforme Malavolta et al. (1989) e Sarruge \& Haag (1974). Os extratos foram obtidos por digestão nitroperclórica e quantificados por espectrofotometria de absorção atômica, com as leituras feitas em aparelho da marca VARIAN Spectr AA 100. Como fonte de radiação foi utilizada lâmpada específica. Por esse processo são determinados os átomos livres do elemento interagindo com a energia em suas diferentes formas, provocando o fenômeno espectroscópio (SILVA, D., 1998).

\section{Avaliação da adequação quanto às necessidades nutricionais diárias para atendimento da meta prevista pelo PNAE}

Para verificar o porcentual de atendimento frente ao recomendado (15\% das necessidades nutricionais (NN diárias), conforme a meta prevista pelo PNAE, foi realizada uma comparação, com base na análise química, entre a $\mathrm{AE}$ fornecida diariamente e o valor médio das NN fixadas para os alunos selecionados segundo a UEM. Considerou-se como consumo adequado de nutrientes oferecidos na alimentação escolar, os valores entre $80 \%$ a $120 \%$ da adequação para energia, proteína, cálcio, magnésio, ferro e zinco, com base nas recomendações do Food and Nutrition Board (2000), utilizando-se o desvio padrão $( \pm 2 \mathrm{DP})$ da necessidade mediana estimada para cada nutriente analisado (FAUSTO, 2003).

\section{Análise estatística}

Os valores obtidos na avaliação da composição química da alimentação escolar foram avaliados por meio da estatística descritiva, utilizando o software SISVAR (FERREIRA, 1999).

\section{RESULTADOS E DISCUSSÃO}

\section{Valor médio das necessidades nutricionais para os alunos do EF}

Apresenta-se na Tabela 1 a denominação de cada escola e respectiva sigla e as médias das necessidades nutricionais para os alunos do EF matriculados nas UEM de Lavras, MG. Observa-se que o valor médio (para todas as escolas), correspondente a $15 \%$ do total energia a ser oferecido na AE, foi de $323 \mathrm{kcal}$; o menor valor (297 kcal) foi encontrado na escola Padre Dehon (PDE) e o maior (346 kcal) na escola Álvaro Botelho (ABO). Em relação ao teor protéico observou-se que o valor previsto para atingir $15 \%$ das $\mathrm{NN}$ variou de $3,76 \mathrm{~g}(\mathrm{OBO})$ a $6,0 \mathrm{~g}$ de proteínas/dia (ABO), sendo a média de $4,57 \mathrm{~g}$ de proteínas/dia, para todos os alunos do EF das UEM de Lavras, em 2004.

Entre os minerais, a serem oferecidos por meio da AE, avaliados no presente estudo, observaram-se as médias: cálcio (162,0mg/dia); magnésio $(32,8 \mathrm{mg} / \mathrm{dia})$; ferro $(1,41 \mathrm{mg} / \mathrm{dia})$; e zinco $(1,07 \mathrm{mg} / \mathrm{dia})$. Vale ressaltar que as diferenças observadas entre os valores médios do cálculo das necessidades nutricionais, para os diferentes nutrientes analisados e valor energético para cada UEM deve-se ao fato dessas serem fundamentadas em diferentes faixas etárias e sexo.

Composição química da alimentação escolar e adequação ao atendimento da meta estabelecida pelo Programa Nacional de Alimentação Escolar

Na Tabela 2 observa-se a composição química da alimentação escolar. Verifica-se que o teor protéico da porção diária da AE oferecida em 2004, nas UEM de Lavras, variou de 4,73g/dia a 13,51g/dia, com média de 7,5g/dia. Os dados referentes à escola Oscar Botelho (OBO) mostraram que o teor protéico da $\mathrm{AE}$ nos dias avaliados variou de $1,96 \mathrm{~g}$ a 10,9g de proteína/dia, apresentando assim, grande variação entre os dias avaliados. Essa mesma situação foi observada nas UEM: PLM, CAIC, JLM, PME, ABO, NCC e NPA.

O teor de lipídeo variou de $1,14 \mathrm{~g}$ a $6,29 \mathrm{~g}$, sendo a média de 3,2g2,7 de lipídeo/ dia; enquanto o teor de carboidratos oscilou de 48,5g a 23,36g, sendo a média de $32,4 \mathrm{~g} \pm 13,3$ por porção diária de AE. Cada um desses nutrientes (proteínas, carboidratos e lipídeos), ao ser absorvido pelo organismo tem finalidades específicas. Assim, a proteína será utilizada na formação e reparação de células; o carboidrato e o lipídeo serão utilizados para o fornecimento de energia imediata e armazenamento do restante, como glicogênio e tecido adiposo, respectivamente (MAHAN \& ESCOTT-STUMP, 2000). 
Tabela 1 - Denominação e sigla das unidades escolares municipais (UEM) e distribuição do valor médio das necessidades nutricionais (15\%) para alunos do ensino fundamental (EF) matriculados nas UEM, urbanas e rurais, de Lavras, MG, no ano de 2004, para atingir a meta prevista pelo Programa Nacional de Alimentação Escolar (PNAE)

\begin{tabular}{|c|c|c|c|c|c|c|}
\hline \multirow{2}{*}{$\begin{array}{l}\text { Unidade escolar municipal } \\
\text { (Sigla) }\end{array}$} & \multicolumn{6}{|c|}{$\begin{array}{l}\text { Média das necessidades nutricionais }(\mathrm{NN})^{1} \text { para os alunos do EF das unidades escolares } \\
\text { municipais de Lavras, MG, para atendimento da meta de fornecer } 15 \% \text { das NN }\end{array}$} \\
\hline & $\begin{array}{l}\text { Energia } \\
\text { (Kcal) }\end{array}$ & $\begin{array}{l}\text { Proteína } \\
(\mathrm{g})\end{array}$ & $\begin{array}{l}\text { Cálcio } \\
(\mathrm{mg})\end{array}$ & $\begin{array}{l}\text { Magnésio } \\
(\mathrm{mg})\end{array}$ & $\begin{array}{l}\text { Ferro } \\
(\mathrm{mg})\end{array}$ & $\begin{array}{c}\text { Zinco } \\
(\mathrm{mg})\end{array}$ \\
\hline Paulo L. Menicucci $\left(\right.$ PLM) ${ }^{u}$ & 308,85 & 3,80 & 150,61 & 25,93 & 1,40 & 0,94 \\
\hline Itália C. Franco (CAIC) ${ }^{\mathrm{u}}$ & 333,00 & 4,70 & 168,75 & 33,97 & 1,42 & 1,10 \\
\hline Doutora Dâmina (DDA) ${ }^{\mathrm{u}}$ & 313,39 & 4,24 & 165,53 & 29,83 & 1,34 & 1,02 \\
\hline Padre Dehon $(\mathrm{PDE})^{\mathrm{u}}$ & 297,27 & 3,87 & 154,09 & 27,00 & 1,36 & 0,95 \\
\hline Oscar Botelho (OBO $)^{\mathrm{u}}$ & 300,58 & 3,76 & 149,41 & 26,32 & 1,40 & 0,93 \\
\hline .P J. L. de Mesquita (JLM) ${ }^{\mathrm{u}}$ & 308,43 & 4,45 & 171,56 & 31,37 & 1,30 & 1,07 \\
\hline Paulo Menicucci (PME) ${ }^{\mathrm{u}}$ & 326,18 & 4,71 & 171,81 & 33,87 & 1,37 & 1,11 \\
\hline José Serafim (JSE) $^{\mathrm{u}}$ & 331,87 & 4,65 & 164,19 & 33,88 & 1,48 & 1,08 \\
\hline Vale do Sol (VSO) $^{\mathrm{u}}$ & 317,44 & 4,13 & 162,85 & 28,92 & 1,33 & 1,01 \\
\hline Francisco Sales (FSA) $^{\mathrm{u}}$ & 322,79 & 3,96 & 155,29 & 27,76 & 1,37 & 0,97 \\
\hline Álvaro Botelho $(\mathrm{ABO})^{\mathrm{u}}$ & 346,35 & 6,00 & 169,03 & 45,08 & 1,57 & 1,31 \\
\hline Cajuru do Cervo (NCC) $)^{r}$ & 323,66 & 4,83 & 173,33 & 35,49 & 1,44 & 1,13 \\
\hline Lagoinha $(\mathrm{NLA})^{\mathrm{r}}$ & 330,86 & 4,80 & 169,03 & 34,96 & 1,46 & 1,11 \\
\hline Cachoeirinha $(\mathrm{NCA})^{\mathrm{r}}$ & 335,90 & 5,03 & 113,10 & 36,76 & 1,43 & 1,16 \\
\hline Paiol (NPA) ${ }^{r}$ & 338,02 & 5,10 & 177,55 & 37,21 & 1,44 & 1,16 \\
\hline Itirapuan $(\mathrm{NIT})^{\mathrm{r}}$ & 334,99 & 5,10 & 175,88 & 37,41 & 1,46 & 1,16 \\
\hline Média geral & 323,10 & 4,57 & 162,00 & 32,86 & 1,41 & 1,07 \\
\hline DP & 14,2 & 0,60 & 15,7 & 5,14 & 0,07 & 0,10 \\
\hline
\end{tabular}

'Recomendações nutricionais: baseadas na RDA/1989 (NRC, 1989) para calorias e para proteína e minerais na DRIs /2001 e DRIs/ 2002 (Food and Nutrition Board, Institute of Medicine, National Academies)

${ }^{\mathrm{u}}$ Escolas urbanas ${ }^{\mathrm{r}}$ Escolas rurais

O peso médio da porção da $\mathrm{AE}$ oferecida aos alunos matriculados nas escolas localizadas na área urbana variou de $148 \mathrm{~g} /$ dia (ABO) a $216 \mathrm{~g} /$ dia (CAIC), com média de $187 \mathrm{~g} /$ dia. As escolas da área urbana que apresentaram maior variação quanto ao peso da porção foram PLM, JLM, PME e ABO. Observou-se, para as escolas da área rural, quanto ao peso da porção diária de alimentação, que o valor médio era de 194g/dia, sendo o menor valor para NLA de 180g/ dia e o maior para o NCA de 198g/dia.

Quanto à densidade energética (D) observaram-se valores entre $0,62 \mathrm{kcal} / \mathrm{g}$ (PDE) e 1,42kcal/g (PLM), sendo o valor médio de $1,05 \mathrm{kcal} / \mathrm{g} \pm 0,40$. Baxter (1997) classifica as dietas segundo a D em: hipocalórica $(0,6$ a 0,8$)$; normocalórica ( 0,9 a 1,2); hipercalórica (1,3 a 1,5). Dentre as 16 UEM avaliadas, oito apresentaram o valor de D menor que um, sendo quatro localizadas no meio rural. Ello-Martin et al. (2005) relatam a importância da composição do alimento (umidade e porcentual de macronutrientes) e do tamanho da porção ingerida na manutenção do peso corporal. Sendo que entre os componentes do alimento, o alto porcentual de água reduz a densidade energética. No presente estudo as porções da alimentação escolar apresentaram teor de umidade entre $89,9 \mathrm{~g} /$ porção (ABO) a $182,4 \mathrm{~g} /$ porção (CAIC), sendo o valor médio de $140,5 \mathrm{~g} /$ porção \pm 35 . A AE oferecida pelo CAIC apresentou maior teor de umidade $(182,4 \mathrm{~g} /$ porção) e menor D $(0,62 \mathrm{kcal} / \mathrm{g})$ corroborando com os relatos de Ello-Martin et al. (2005). Bennett et al. (1999) ao avaliar o efeito da densidade energética e viscosidade da alimentação sobre o consumo energético diário total, concluíram que a dieta que apresentava alta densidade energética e alta viscosidade aumentava a ingestão calórica das crianças.

$A$ variação nos teores de macronutrientes na $\mathrm{AE}$ oferecida deve-se ao fato das UEM de Lavras, MG, não apresentarem uma padronização da quantidade per capita durante o preparo e distribuição da $\mathrm{AE}$ aos alunos do $\mathrm{EF}$ e, 
Tabela 2 - Valores médios da composição química, energia e densidade energética na matéria integral da porção diária (g/porção) da alimentação escolar (AE) oferecida aos alunos do ensino fundamental (EF) das unidades escolares municipais urbanas e rurais, de Lavras, MG, no ano de 2004.

\begin{tabular}{|c|c|c|c|c|c|c|c|c|c|}
\hline \multirow[t]{2}{*}{$\begin{array}{l}\text { Unidade escolar municipal } \\
\text { (UEM) }\end{array}$} & \multirow{2}{*}{$\begin{array}{l}\text { Peso da } \\
\text { porção } \\
\text { (g/dia) }\end{array}$} & \multicolumn{6}{|c|}{$\begin{array}{c}\text { Composição química }{ }^{1} \text { da AE } \\
\text { (média de } 4 \text { coletas por UEM) (g/porção/dia) }\end{array}$} & \multirow{2}{*}{$\begin{array}{l}\text { Energia } \\
\text { (kcal/dia) }\end{array}$} & \multirow[t]{2}{*}{$\begin{array}{l}\text { Densidade } \\
\text { energética }^{4}\end{array}$} \\
\hline & & Umidade & Lipídeos & Proteína $^{2}$ & Cinza & Fibra & E.N.N. ${ }^{3}$ & & \\
\hline Paulo L. Menicucci / PLM ${ }^{\mathrm{u}}$ & 162 & 110,7 & 4,65 & 6,85 & 0,74 & 1,58 & 37,68 & 219,9 & 1,42 \\
\hline Itália C. Franco/ CAIC ${ }^{\text {u }}$ & 216 & 182,4 & 1,63 & 4,9 & 0,51 & 1,9 & 24,94 & 134,1 & 0,63 \\
\hline Doutora Dâmina/ DDA ${ }^{u}$ & 200 & 134,1 & 4,97 & 7,64 & 1,29 & 3,25 & 48,50 & 269,1 & 1,33 \\
\hline Padre Dehon/ PDE ${ }^{\mathrm{u}}$ & 212 & 178,4 & 1,14 & 6,25 & 0,89 & 2,00 & 23,36 & 128,7 & 0,62 \\
\hline Oscar Botelho/ OBO ${ }^{\text {u }}$ & 195 & 153,0 & 1,94 & 5,71 & 0,78 & 0,97 & 32,64 & 170,9 & 0,87 \\
\hline P. J. L. Mesquita/ JLM ${ }^{\text {u }}$ & 163 & 112,1 & 4,79 & 8,76 & 3,11 & 2,12 & 31,57 & 204,4 & 1,35 \\
\hline Paulo Menicucci/ PME ${ }^{\mathrm{u}}$ & 173 & 126,8 & 3,26 & 7,76 & 0,60 & 2,06 & 32,04 & 188,5 & 1,11 \\
\hline José Serafim/ JSE ${ }^{\text {u }}$ & 198 & 154,0 & 2,27 & 7,64 & 2,13 & 2,17 & 29,80 & 170,2 & 0,87 \\
\hline Vale do Sol/ $\mathrm{VSO}^{\text {u }}$ & 173 & 127,8 & 3,71 & 7,68 & 1,09 & 2,37 & 30,31 & 185,4 & 1,08 \\
\hline Francisco Sales/FSA ${ }^{\text {u }}$ & 179 & 128,7 & 4,53 & 9,08 & 1,24 & 2,36 & 32,57 & 207,4 & 1,16 \\
\hline Álvaro Botelho/ $\mathrm{ABO}^{\mathrm{u}}$ & 148 & 89,9 & 6,29 & 13,51 & 1,14 & 2,09 & 34,98 & 250,6 & 1,77 \\
\hline Cajuru do Cervo/ $\mathrm{NCC}^{\mathrm{r}}$ & 195 & 149,6 & 2,29 & 4,89 & 0,89 & 2,84 & 33,98 & 176,1 & 0,89 \\
\hline Lagoinha/ NLA $^{\mathrm{r}}$ & 180 & 135,8 & 3,40 & 6,89 & 0,43 & 1,87 & 31,57 & 184,5 & 1,03 \\
\hline Cachoeirinha/ $\mathrm{NCA}^{\mathrm{r}}$ & 198 & 147,2 & 2,28 & 9,00 & 1,90 & 1,80 & 35,36 & 198,0 & 0,98 \\
\hline Paiol/ NPA ${ }^{\mathrm{r}}$ & 191 & 148,9 & 1,85 & 4,73 & 0,39 & 2,05 & 32,51 & 165,7 & 0,86 \\
\hline Itirapuan/ NPA ${ }^{\mathrm{r}}$ & 209 & 162,9 & 3,02 & 7,94 & 0,91 & 6,43 & 27,85 & 170,3 & 0,82 \\
\hline Média total & 187 & 140,5 & 3,2 & 7,5 & 1,1 & 2,4 & 32,4 & 189,0 & 1,05 \\
\hline DP & 32,5 & 35,0 & 2,7 & 3,4 & 1,2 & 2,3 & 13,3 & 68,77 & 0,40 \\
\hline
\end{tabular}

${ }^{1}$ Média da composição química (g/100g na matéria integral) das amostras da alimentação escolar coletadas aleatoriamente, no ano de 2004. ${ }^{2}$ Proteína (N X 6,25)

${ }^{3}$ E.N.N.= extrato não nitrogenado (calculado por diferença)

${ }^{4}$ Densidade energética $=$ Energia $(\mathrm{kcal}) /$ Peso da porção $(\mathrm{g})$

${ }^{\mathrm{u}}$ Escolas urbanas ${ }^{\mathrm{r}}$ Escolas rurais

também não seguir nenhuma programação de cardápios balanceados, segundo o perfil (idade, sexo, número de alunos) dos estudantes matriculados nas mesmas. Essa constatação resulta da falta de padronização das porções alimentícias que eram oferecidas aos estudantes em UEM, bem como pela inexistência de balanceamento dos cardápios diários da $\mathrm{AE}$. $\mathrm{O}$ desequilíbrio quanto à quantidade de proteína a ser oferecida diariamente na $\mathrm{AE}$ não deveria ocorrer, em virtude do papel desempenhado por esse nutriente no corpo humano e, principalmente pelas faixas etárias (crianças e adolescentes) que são beneficiadas pelo Programa. Em virtude de crianças e adolescentes estarem em fase de crescimento o equilíbrio entre a distribuição dos nutrientes é de grande importância.

De acordo com os dados, percebe-se que a maioria das escolas pesquisadas não tinha uma padronização da alimentação média diária per capita. Para atender de forma adequada, diariamente, às $\mathrm{NN}$ dos estudantes, torna-se necessário controlar rigorosamente as porções dos alimentos servidos nas UEM, associando não só a qualidade dos alimentos oferecidos aos alunos como também a quantidade, que é fundamental para as diferentes faixas etárias (crianças e adolescentes) dos alunos matriculados nas mesmas. O valor energético da alimentação escolar na porção diária e porcentual de adequação encontra-se na Tabela 3.

A recomendação da proporção de energia para a faixa etária das crianças e adolescentes é de $20 \%$ a $30 \%$ provenientes dos lipídeos, $10 \%$ a $15 \%$ da proteína e $50 \%$ a $60 \%$ dos carboidratos (FAUSTO, 2003). O cálculo da distribuição energética da porção da $\mathrm{AE}$ revelou que 15,2\% das calorias eram provenientes dos lipídeos, 15,9\% de proteínas $68,7 \%$ da fração glicídica. Ao comparar com a recomendação observa-se que o teor lipídico ficou abaixo da recomendação, a proteína ultrapassou ligeiramente o percentual e a fração glicídica ficou acima do previsto, verificando-se assim um desequilíbrio entre a distribuição porcentual dos macronutrientes. Uma adequada distribuição dos macronutrientes fornecidos nos lanches e refeições, para as distintas faixas etárias estudadas (crianças e 
Tabela 3 - Porcentual de adequação médio do valor energético e teor protéico das porções diárias da alimentação escolar (AE) oferecidas aos alunos do ensino fundamental das unidades municipais de ensino, urbanas e rurais de Lavras, MG, em 2004.

\begin{tabular}{|c|c|c|c|}
\hline \multirow[t]{2}{*}{$\begin{array}{l}\text { Unidade de ensino municipal } \\
\text { (UEM) }\end{array}$} & \multirow[t]{2}{*}{ Identificação da UEM } & \multicolumn{2}{|c|}{$\begin{array}{l}\text { Percentual de adequação para o atendimento diário de } \\
15 \% \text { das necessidades nutricionais dos alunos do EF } \\
\text { conforme proposto pelo PNAE }\end{array}$} \\
\hline & & Adequação energética (\%) & Adequação protéica (\%) \\
\hline Paulo L. Menicucci ${ }^{\mathrm{u}}$ & PLM & 71,04 & 180,3 \\
\hline Itália Cautiero Franco $^{\text {u }}$ & CAIC & 40,12 & 104,3 \\
\hline Doutora Dâmina $^{u}$ & DDA & 85,96 & 180,2 \\
\hline Padre Dehon $^{\mathrm{u}}$ & PDE & 43,29 & 161,5 \\
\hline Oscar Botelho $^{\mathrm{u}}$ & $\mathrm{OBO}$ & 56,66 & 151,9 \\
\hline P. J.Luiz de Mesquita ${ }^{u}$ & JLM & 66,40 & 196,9 \\
\hline Paulo Menicucci $^{\mathrm{u}}$ & PME & 57,91 & 164,3 \\
\hline José Serafim ${ }^{\mathrm{u}}$ & JSE & 51,31 & 164,3 \\
\hline Vale do Sol ${ }^{\mathrm{u}}$ & VSO & 58,37 & 186,0 \\
\hline Francisco Sales $^{\mathrm{u}}$ & FSA & 64,22 & 229,3 \\
\hline Álvaro Botelho ${ }^{u}$ & $\mathrm{ABO}$ & 72,38 & 225,2 \\
\hline Cajuru do Cervo $^{r}$ & $\mathrm{NCC}$ & 54,47 & 101,2 \\
\hline Lagoinha $^{r}$ & NLA & 55,79 & 143,5 \\
\hline Cachoeirinha $^{r}$ & NCA & 59,03 & 178,9 \\
\hline Paiol $^{\mathrm{r}}$ & NPA & 49,08 & 92,7 \\
\hline Itirapuan $^{\mathrm{r}}$ & NIT & 50,81 & 155,7 \\
\hline Média geral & & 58,49 & 165,3 \\
\hline Desvio Padrão & & 11,5 & 39,6 \\
\hline
\end{tabular}

${ }^{1}$ Porcentual de adequação (80\% a 120\%) do total de calorias e proteínas oferecidas na alimentação escolar durante o ano de 2004, nas UEM de Lavras, MG, aos alunos do EF

${ }^{2}$ Recomendações nutricionais para calorias, baseadas na RDA/1989 (NRC, 1989) e para proteínas nas DRIs/2001 (FISBERG et al., 2005). ${ }^{\mathrm{u}}$ Escolas urbanas ${ }^{\mathrm{r}}$ Escolas rurais

adolescentes) é de grande importância, pois lipídeos e carboidratos são os nutrientes responsáveis pelo fornecimento de calorias ao organismo. No processo metabólico existe uma correlação entre eles, fazendo com que, na falta de um, o organismo utilize o outro para a produção de energia (MAHAN \& ESCOTT-STUMP, 2000), além das funções específicas desempenhadas (fonte de ácidos graxos essências, veículo de vitaminas lipossolúveis) pelos lipídeos conforme relato de Prentice \& Paul (2000).

Os dados referentes à adequação do valor energético e protéico fornecidos pela $\mathrm{AE}$ indicam que as UEM de Lavras não estavam atendendo à meta de

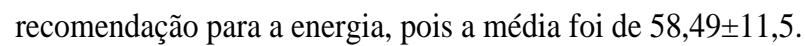
Somente a escola DDA (meio urbano) forneceu calorias, por meio da AE, dentro da faixa de recomendação $(85,96 \%)$ preconizada. Quanto ao teor protéico, esse se encontrava bem acima da média recomendada, e apenas três escolas estavam dentro da faixa de recomendação estabelecida para proteínas.

O baixo porcentual da adequação calórica da alimentação escolar vai ao encontro do consenso existente entre os pesquisadores de que a base do problema nutricional brasileiro está na insuficiência calórica, que afeta de forma acentuada as populações urbanas, agravandose com a densidade populacional das cidades (ANDRADE et al., 2004). É importante ressaltar que, se não houver equilíbrio entre as calorias e o conjunto dos demais nutrientes ingeridos, a proteína poderá ser utilizada de forma inadequada ou alterar o uso de outros nutrientes. Para a síntese protéica há necessidade de energia dietética, sendo essa síntese sensível ao déficit calórico. Assim, o balanço energético orgânico é um fator importante na determinação do balanço de nitrogênio, influenciando na utilização das proteínas dietéticas (MAHAN \& ESCOTT-STUMP, 2000). 
O fornecimento de energia abaixo da recomendação também foi observado por Silva, M. (1998), ao avaliar a alimentação de 257 crianças pertencentes aos quatro Centros Integrados de Educação Pública (CIEPs) de Americana, SP, onde a dieta dos escolares mostrou-se, em média, deficiente em energia. As refeições consumidas no âmbito dos CIEPs não alcançaram 70\% de adequação, verificando, ainda, que, inversamente, o conteúdo protéico das dietas apresentou-se muito acima do preconizado. Em outro estudo, Salay \& Carvalho (1995) avaliando a adequação calórica do programa de merenda escolar do município de Campinas, SP, encontraram valores baixos para a adequação, sendo a média de 48,6\% $\pm 17,3$ de energia, e de $52,7 \% \pm 17,2$ para proteína.

A composição mineral da AE oferecida nas UEM de Lavras, MG, encontra-se na Tabela 4. O fornecimento médio dos minerais: cálcio, magnésio, ferro e zinco foram de $72,85 \mathrm{mg}, 16,66 \mathrm{mg}, 2,2 \mathrm{mg}$ e $1,44 \mathrm{mg}$, respectivamente. Quanto ao Ca, verificou-se que o menor valor foi o apresentado pela escola OBO $(38,5 \mathrm{mg} / \mathrm{dia})$ e o maior $(135,7 \mathrm{mg} / \mathrm{dia})$ da JLM e que somente o NCA atingiu a meta de recomendações propostas pelo PNAE. As escolas JLM e FSA apresentaram valores acima das recomendações para o Mg e somente o NCA ficou dentro da faixa de adequação. Quanto ao ferro, todas as escolas avaliadas atingiram a meta. Em relação ao zinco as escolas DDA, OBO e NPA apresentaram valores inferiores aos recomendados; enquanto as escolas DDA, OBO e NPA ficaram entre os valores médios de adequação ( 80 a 120\%) e as demais escolas estudadas apresentaram valores acima do preconizado. Os valores médios de adequação para os minerais, no presente estudo, foram da ordem de $46,1 \% \pm 21$ para o $\mathrm{Ca}$ e de

Tabela 4 - Valores médios e porcentuais de adequação ${ }^{1}$ da composição mineral na matéria integral (mg/porção) contida nas porções médias diárias da alimentação escolar (AE) oferecidas aos alunos do ensino fundamental nas UEM, urbanas e rurais, de Lavras, MG, no ano de 2004.

\begin{tabular}{|c|c|c|c|c|c|c|c|c|}
\hline \multirow{4}{*}{ UEM } & \multicolumn{8}{|c|}{ Composição mineral (mg/porção diária) ${ }^{2}$} \\
\hline & \multicolumn{4}{|c|}{ Macrominerais } & \multicolumn{4}{|c|}{ Microminerais } \\
\hline & \multicolumn{2}{|c|}{ Cálcio } & \multicolumn{2}{|c|}{ Magnésio } & \multicolumn{2}{|c|}{ Ferro } & \multicolumn{2}{|c|}{ Zinco } \\
\hline & $\begin{array}{c}\text { Oferecido } \\
\text { (mg/dia) }\end{array}$ & $\begin{array}{c}\text { Adequação } \\
(\%)\end{array}$ & $\begin{array}{c}\text { Oferecido } \\
\text { (mg/dia) }\end{array}$ & $\begin{array}{c}\text { Adequação } \\
(\%)\end{array}$ & $\begin{array}{c}\text { Oferecido } \\
\text { (mg/dia) }\end{array}$ & $\begin{array}{c}\text { Adequação } \\
(\%)\end{array}$ & $\begin{array}{c}\text { Oferecido } \\
\text { (mg/dia) }\end{array}$ & $\begin{array}{c}\text { Adequação } \\
(\%)\end{array}$ \\
\hline PLM & 91,36 & 60,7 & 8,62 & 33,2 & 3,35 & 239,3 & 3,52 & 374,5 \\
\hline CAIC & 49,07 & 29,1 & 9,28 & 27,3 & 2,60 & 183,1 & 0,89 & 80,9 \\
\hline DDA & 85,99 & 52,0 & 5,55 & 18,6 & 1,39 & 103,7 & 0,70 & 68,6 \\
\hline PDE & 40,14 & 26,1 & 13,17 & 48,8 & 1,11 & 81,6 & 0,95 & 100,0 \\
\hline OBO & 38,50 & 26,0 & 5,01 & 19,0 & 1,35 & 96,4 & 0,31 & 33,3 \\
\hline JLM & 135,72 & 79,1 & 51,82 & 165,2 & 2,81 & 216,2 & 1,34 & 141,1 \\
\hline PME & 62,62 & 36,5 & 5,36 & 15,8 & 1,12 & 81,7 & 1,01 & 125,2 \\
\hline JSE & 67,07 & 41,2 & 17,94 & 53,0 & 2,24 & 151,4 & 1,13 & 104,6 \\
\hline VSO & 105,84 & 65,0 & 5,25 & 18,2 & 1,91 & 143,6 & 1,53 & 151,5 \\
\hline FSA & 89,26 & 57,5 & 35,39 & 127,5 & 2,26 & 165,0 & 1,66 & 171,1 \\
\hline $\mathrm{ABO}$ & 89,32 & 52,8 & 14,65 & 32,5 & 3,98 & 253,5 & 2,85 & 217,6 \\
\hline $\mathrm{NCC}$ & 42,74 & 24,7 & 12,78 & 36,0 & 1,68 & 116,7 & 1,53 & 135,4 \\
\hline NLA & 61,12 & 36,2 & 13,94 & 40,0 & 2,28 & 156,2 & 2,28 & 205,4 \\
\hline $\mathrm{NCA}$ & 106,60 & 94,3 & 34,11 & 93,0 & 3,66 & 255,9 & 2,01 & 173,3 \\
\hline NPA & 45,45 & 25,6 & 8,91 & 24,0 & 1,17 & 81,3 & 0,32 & 27,58 \\
\hline NIT & 54,81 & 31,2 & 24,73 & 66,0 & 2,32 & 158,9 & 0,95 & 81,9 \\
\hline Média & 72,85 & 46,1 & 16,66 & 51,1 & 2,20 & 156,0 & 1,44 & 134,6 \\
\hline DP & 28,6 & 21,0 & 13,4 & 42,9 & 0,91 & 60,8 & 0,88 & 84,2 \\
\hline
\end{tabular}

${ }^{1}$ Porcentual de adequação (80\% a 120\%) do total de minerais oferecidos na alimentação escolar durante o ano de 2004, nas UEM de Lavras, MG, aos alunos do EF para atendimento da meta de fornecer 15\% das necessidades nutricionais, conforme previsto pelo PNAE, para cada UEM

${ }^{2}$ Composição química mineral média das amostras da alimentação escolar coletadas aleatoriamente durante o ano de 2004 nas UEM de Lavras, MG.

${ }^{\mathrm{u}}$ Escolas urbanas ${ }^{\mathrm{r}}$ Escolas rurais 
$51,1 \% \pm 42,9$ para o $\mathrm{Mg}$. O Fe e o $\mathrm{Zn}$ apresentaram valores médios acima do previsto para a alimentação escolar, sendo de $156,0 \% \pm 60,8$ e $134,6 \% \pm 84,2$ respectivamente.

As constatações quanto à falta de padronização das porções alimentícias e balanceamento dos cardápios diários oferecidas na alimentação escolar, poderiam ser corrigidas com efetivo acompanhamento por profissionais da área de alimentação e nutrição, no tocante às adequações quanto ao planejamento de cardápios e gerenciamento dos recursos humanos pertencentes aos SAE. Segundo Camargo (2003), ao planejar um cardápio deve-se basear na pirâmide dos alimentos, um guia de alimentação elaborado para auxiliar na escolha dos alimentos, que devem estar presentes nas refeições do nosso dia-a-dia, garantindo assim uma alimentação saudável.

\section{CONCLUSÃO}

A meta de fornecer $15 \%$ das necessidades nutricionais dos alunos do ensino fundamental na alimentação escolar das unidades de ensino municipal de Lavras, MG, no ano de 2004, não foi totalmente atingida, pois a maioria das adequações nutricionais ficou fora da faixa recomendada. Das dezesseis escolas estudadas o teor de energia e cálcio encontrava-se abaixo do recomendado em quinze escolas, sendo que apenas uma (meio urbano) atendeu à proporção de calorias e uma do meio rural atendeu quanto ao teor de cálcio. Em três unidades escolares (duas urbanas e uma rural) o teor de zinco ficou abaixo da meta prevista. Para o magnésio só três escolas (duas do meio urbano e uma do rural) atingiram a meta; as metas de oferecimento de proteína e ferro foram atendidas por todas as escolas, ficando acima do preconizado pelo Programa Nacional de Alimentação Escolar.

\section{REFERÊNCIAS BIBLIOGRÁFICAS}

ANDRADE, F. F.; FERRO, V. C.; SILVA, V. G. da; FALCÃO, M. C. Merenda escolar: municipalização e atribuições do nutricionista. Higiene Alimentar, São Paulo, v. 18, n. 124, p. 43-49, 2004

ASSEMBLÉIA LEGISLATIVA DE MINAS GERAIS. Perfil dos municípios mineiros. Disponível em: 4http://Www.almg.gov.br/munmg. Acesso em: 10 out. 2005 .

ASSOCIATION OF OFFICIAL ANALYTICAL CHEMISTS. Official methods of analytical. 15. ed. Washington, DC, 1990. v. 2.
BAXTER, Y. C. Dietas enterais: composição, variedades e disponibilidade de dietas no mercado nacional. In: PINOTTI, H. W. Nutrição enteral em cirurgia. São Paulo: BYK, 1997. p. 149-161.

BENNETT, V. A.; MORALES, E.; GONZÁLEZ, J.; PEERSON, J. M.; ROMANÃ, G. L. de; BROWN, K. H. Effects of dietary viscosityand energy density on total daily energy consumption by young Peruvian children. American Journal Clinical Nutrition, New York, v. 70, n. 2, p. 285-291, 1999.

BRASIL. Ministério da Educação. Resolução FNDE /CD $\mathbf{N}^{\circ}$ 038, de 23 de agosto de 2004. Programa Nacional de Alimentação Escolar - PNAE. Brasília, DF, 2004. Disponível em: xhttp://www.fnde.govbr/legislação/pnae/htlmi >. Acesso em: 20 set. 2005.

CAMARGO, F. L. F. Planejamento de cardápios. Pelotas: UFPel, 2003. 178 p.

ELLO-MARTIN, J. A.; LEDIKWE, J. H.; ROLLS, B. J. The influencie of food portion size and energy density on energy intake: implications for weigth management. American Journal Clinical Nutrition, New York, v. 82, p. 236S-241S, 2005. Supplement.

FAUSTO, M. A. Planejamento de dietas e da alimentação. Rio de Janeiro: Revinter, 2003. 138 p.

FERREIRA, D. F. SISVAR. Versão 4.3. Lavras: UFLA/DEX, 1999. CD-ROM.

FISBERG, R. M.; SLATER, B.; MARCHIONI, D. M. L.; MARTINI, L. A. Recomendações nutriocionais. In: Inquéritos alimentares: métodos e bases científicas. Barueri: Manole, 2005. p. 190-236.

FLÁVIO, E. F. Avaliação quimica e sensorial da merenda escolar e do estado nutricional de alunos do Ensino fundamental de uma Escola Estadual de Lavras, MG. 2002. 128 p. Dissertação (Mestrado em Ciência dos Alimentos) Universidade Federal de Lavras, Lavras, 2002.

FOOD AND NUTRITION BOARD. National Research Council. Insitute of Medicine. Dietary reference intakes: applications in dietary assessment. Washington, DC: National Academy, 2000.

FUNDO NACIONAL DE DESENVOLVIMENTO DO ENSINO. Merenda escolar. Disponível em: <http:// iwww.fnde.gov.bris. Acesso em: 20 jul. 2005. 
KAMER, J. H. van de; GINKEL, L. van. Rapid determition of crude fiber in cereais. Cereal Chemistry, Saint Paul, v. 29, n. 4, p. 239-251, July/Aug. 1952.

MAHAN, L. K.; ESCOTT-STUMP, S. Krause alimentos, nutrição e dietoterapia. Traduzido por Favano A. 9. ed. São Paulo: Roca, 2000. 179 p. Título original: Krause's food, nutrition e diety therapy.

MALAVOLTA, E.; VITTI, G. C.; OLIVEIRA, S. A. Avaliação do estado nutricional de plantas. Piracicaba: Potafos, 1989. $201 \mathrm{p}$.

NATIONAL RESEARCH COUNCIL. Recommended dietary allowances. 10. ed. Washington, DC: National Academic Science, 1989. 284 p.

OSBORNE, D. R.; VOOGT, P. The analysis of nutrient in foods. London: Academic, 1978.
PRENTICE, A. M.; PAUL, A. Fat and energy needs of children in developing countries. American Journal Clinical Nutrition, New York, v. 72, p. 1253S-1265S, 2000. Supplement.

SALAY, E.; CARVALHO, J. F. de. Avaliação do programa de merenda escolar do município de Campinas, Brasil. Archivos Latinoamericanos de Nutricion, Caracas, v. 45, n. 3, p. 167-171, jul./set. 1995.

SARRUGE, J. R. R.; HAAG, H. P. Análise química em plantas. Piracicaba: ESALQ/USP, 1974. 56 p.

SILVA, D. J. Análise de alimentos. Viçosa: UFV, 1998. 165 p.

SILVA, M. V. da. Alimentação na escola como forma de atender às recomendações nutricionais de alunos dos Centros Integrado de Educação Pública (CIEPs). Caderno de Saúde Pública, Rio de Janeiro, v. 14, n. 1, jan./mar. 1998. 